\title{
Application of coercimetry to assess the functional properties of materials
}

\author{
Vladimir Kostin ${ }^{1,2}$, Danila Ksenofontov $^{1}$, Olga Vasilenko $^{1,2, *}$, and Alexander Byzov ${ }^{1}$ \\ ${ }^{1}$ M.N. Miheev Institute of Metal Physics of Ural Branch of RAS, 620137, Ekaterinburg, Russia \\ ${ }^{2}$ UrFU, Institute of Physics and Technology, 620002, Ekaterinburg, Russia
}

\begin{abstract}
The purpose of this work is a comparative study of the possibilities of various types of coercimeters to assess the functional properties of ferromagnetic materials. Conducted research have shown that the limitation of the maximum measured value of the coercive force using an attached transducer with a U-shaped electromagnet is due to the lower value of the magnetic resistance of the tested workpiece. The upper limit of measurements of the coercive force using a two-pole transducer is determined by the magnitude of the tangential component of the magnetic field only by the possibility of magnetizing the tested object.
\end{abstract}

\section{Introduction}

Initial $\mu_{a}$ and $\mu_{\max }$ maximum permeabilities, coercive force $H_{c}$, residual magnetization $M_{r}$ (residual induction $B_{r}$ ), hysteresis losses are a sensitive to changes in structure of object magnetic parameters. These properties are extremely dependent on the conditions of production and heat treatment (that is, on the object's microstructure), as well as on the size of the sample. The atoms of the dissolved element, dislocations, grain boundaries, the presence of the second phase and its dispersion have the greatest influence on these properties. By changing the phase state and structure of alloys, it is possible to influence their properties in a wide range of values. It is practicable to change the phase state by choosing the composition of the alloys, and the structure by appropriate treatment: thermal, plastic, thermomagnetic, etc. When studying the relationship between magnetic properties and structure and mechanical properties, exactly the structure-sensitive properties are of direct theoretical and practical interest. As well it should be noted here that the main element of the structure of ferromagnetic materials, which basically determines all their magnetic properties, is the domain structure.

In this case the magnetic permeability and coercive force are determined only by the properties of the material itself and the interaction between electrons and positive ions in the sample.

At present, there is sufficient information on the structure of domains and elementary magnetization processes; however, the current state of the theory does not yet allow one to obtain unambiguous quantitative relationships between the values of magnetic parameters

\footnotetext{
*Corresponding author: vasilenko@imp.uran.ru
} 
and various structure characteristics of materials. In connection with the above, the "correct" measurement of the magnetic properties of matter remains a very urgent problem to this day.

Nowadays, the most common method for local measurement of the coercive force is the method proposed back in the middle of the last century [1, 2], based on magnetizing until saturation of a section of a ferromagnetic object using a U-shaped bipolar electromagnet, which forms a closed magnetic circuit with the tested object, followed by demagnetization and measurements of the demagnetizing current in the coils of the electromagnet, leading to zero flux in this circuit [3-11]. This demagnetizing current $I_{c}$ is proportional to the average value of the coercive force of the magnetized (tested) volume of the tested object. Graduation or calibration is carried out using coercive force standard samples (CFSS). However, the results of such a calibration cannot be used when testing objects that have sizes and shapes that are significantly different from the CFSS.

From theoretical and experimental data, it follows that the measuring capabilities and readings of coercimeters with the measurement of the demagnetizing current are influenced by the size and shape of the tested objects [1-12], the size and shape of the attached electromagnets used [2, 3-5, 10-12], the presence and the size of the gaps in the magnetic circuit "attached transducer - object", the degree of homogeneity of properties in the magnetized volume, the type and characteristics of the zero-indicator of magnetic flux in the circuit "attached transducer - object" [6-8, 11-13]. Coercimeters, in which the procedure of the measurement of demagnetizing current(DC) is used(DC-coercimeters) have become very widespread.

Along with the above, there is a method [12-17], by which is assumed at the moment of zero magnetic flux in the "attached transducer - object" circuit measuring the magnitude of the tangential component of the magnetic field on the surface of the magnetized area of the tested object using small-sized field sensors to determine the coercive force. The magnetic field intensity $H_{t c}$ measured in this way is equal to the coercive force of a homogeneous object (H-coercimeter).

The aim of this work was a comparative study of the possibilities and determination of the prospects of DC-coercimeters and H-coercimeters for assessing the functional properties of ferromagnetic materials.

\section{Samples and Research Methods}

To determine the possibilities of local measurement of the coercive force, samples of three standard sizes were used: a set of standard samples of the CFSS in the form of rectangular parallelepipeds with dimensions of $57 \times 34 \times 7.6 \mathrm{~mm}$ (Table 1), a set of standard samples of the residual magnetic inductance (RMI) in the form of plates with dimensions of $90.0 \times 40.1 \times 4.6 \mathrm{~mm}$ (table 2), quenched from $790{ }^{\circ} \mathrm{C}$ and tempered (aged) at different temperatures of samples from steel H18K9M5T with dimensions of 60x10x6 mm.

The absolute values of the coercive force of the OMI plates and samples of steel N18K9M5T were measured in a closed magnetic circuit (permeameter) using a REMAGRAPH C-500 measuring complex manufactured by Magnet-Physik Dr. Steingroever GmbH, Germany (http://www.magnet-physik.de/1.html). The coercive force of the CFSS samples was measured by pulling the coil off the sample [18] during magnetization in a solenoid with a maximum field of $800 \mathrm{~A} / \mathrm{cm}$. The measurement of the coercive force by the magnitude of the demagnetizing current was carried out using a KIFM-1 coercimeter with a pole section of $20 \times 40 \mathrm{~mm}$, in which a frame ferroprobe is used as a zero-indicator of the magnetic flux $[4,5]$. The measurement of the coercive force by the magnitude of the internal field was carried out using the hardware-software system 
DIUS-1.15M $[13,16]$ and magnetic multitester MMT-3 with a non-electric magnetizing device $[13,19]$

Table 1. Properties of CFSS.

\begin{tabular}{|c|c|c|c|c|}
\hline Sample & Material & $\begin{array}{c}\text { Hardening } \\
\text { temperature, }{ }^{\circ} \mathrm{C}\end{array}$ & $\begin{array}{c}\text { Tempering } \\
\text { temperature, }{ }^{\circ} \mathrm{C}\end{array}$ & $\begin{array}{c}\mathrm{Hc}, \\
\mathrm{A} / \mathrm{cm}\end{array}$ \\
\hline K1 & Steel 10 GOST 1050 & - & - & 2,7 \\
\hline K2 & Steel 20 GOST 1050 & - & - & 2,9 \\
\hline K3 & Steel 35 GOST 1050 & - & - & 6,3 \\
\hline K4 & Steel 40 GOST 1050 & - & - & 6,1 \\
\hline K5 & Steel 45 GOST 1050 & - & - & 13,7 \\
\hline K6 & Steel ShH15SG GOST 801 & 835 & 600 & 19,8 \\
\hline K7 & Steel ShH15 SG GOST 801 & 835 & 300 & 29,2 \\
\hline K8 & Steel ShH15SG GOST 801 & 835 & 215 & 36,8 \\
\hline K9 & Steel ShH15SG GOST 801 & 835 & 180 & 38,2 \\
\hline K10 & Steel ShH15SG GOST 801 & 835 & 100 & 46,6 \\
\hline
\end{tabular}

Table 2. Properties of RMI.

\begin{tabular}{|c|c|c|c|c|c|c|}
\hline Sample & $\mathrm{Br}, \mathrm{T}$ & Material & $\begin{array}{c}\text { T hard., time, } \\
\text { Coolant }\end{array}$ & T temp. & Additional & $\mathrm{Hc}, \mathrm{A} / \mathrm{cm}$ \\
\hline RMI 1 & 0,21 & Steel 95H18 GOST 5632 & $\begin{array}{c}1110^{\circ} \mathrm{C} \\
10 \text { min } \\
\text { Oil }\end{array}$ & $250^{\circ} \mathrm{C}$ & $\begin{array}{c}\text { cold: } \\
-14^{\circ} \mathrm{C} \\
40 \text { hours }\end{array}$ & 83,4 \\
\hline RMI 2 & 0,36 & Steel 95H18 GOST 5632 & $\begin{array}{c}1090^{\circ} \mathrm{C} \\
10 \text { min } \\
\text { Oil }\end{array}$ & $400{ }^{\circ} \mathrm{C}$ & $\begin{array}{c}\text { cold: } \\
-14{ }^{\circ} \mathrm{C} \\
40 \text { hours }\end{array}$ & 86,2 \\
\hline RMI 3 & 0,53 & Steel 95H18 GOST 5632 & $\begin{array}{c}1070^{\circ} \mathrm{C} \\
10 \text { min } \\
\text { Oil }\end{array}$ & $200^{\circ} \mathrm{C}$ & & 74,5 \\
\hline RMI 4 & 0,83 & Steel 95H18 GOST 5632 & $\begin{array}{l}1070^{\circ} \mathrm{C} \\
10 \text { min } \\
\text { Oil }\end{array}$ & $550^{\circ} \mathrm{C}$ & & 27,8 \\
\hline RMI 5 & 0,93 & $\begin{array}{c}\text { Steel 65G } \\
\text { GOST } 14959\end{array}$ & $\begin{array}{c}870^{\circ} \mathrm{C} \\
10 \mathrm{~min} \\
\text { Oil } \\
\end{array}$ & $200^{\circ} \mathrm{C}$ & & 32,3 \\
\hline RMI 6 & 1,08 & $\begin{array}{c}\text { Steel } 10 \text { (pipe) } \\
\text { GOST } 1050\end{array}$ & $\begin{array}{l}930^{\circ} \mathrm{C} \\
15 \mathrm{~min} \\
\text { Oil }\end{array}$ & $400{ }^{\circ} \mathrm{C}$ & & 8,89 \\
\hline RMI 7 & 1,30 & $\begin{array}{c}\text { Steel } 10 \text { (pipe) } \\
\text { GOST } 1050\end{array}$ & $\begin{array}{c}930^{\circ} \mathrm{C} \\
15 \text { min } \\
\text { Oil } \\
\end{array}$ & $500^{\circ} \mathrm{C}$ & & 7,86 \\
\hline RMI 8 & 1,45 & $\begin{array}{c}\text { Steel 65G } \\
\text { GOST } 14959\end{array}$ & $\begin{array}{c}870{ }^{\circ} \mathrm{C} \\
10 \text { min } \\
\text { Oil }\end{array}$ & $400{ }^{\circ} \mathrm{C}$ & & 14,4 \\
\hline RMI 9 & 1,52 & $\begin{array}{c}\text { Steel } 10 \text { (pipe) } \\
\text { GOST } 1050\end{array}$ & $\begin{array}{l}930^{\circ} \mathrm{C} \\
15 \text { min } \\
\text { Oil }\end{array}$ & $600^{\circ} \mathrm{C}$ & & 5,95 \\
\hline RMI 10 & 1,55 & $\begin{array}{c}\text { Steel 65G } \\
\text { GOST } 14959\end{array}$ & $\begin{array}{l}870^{\circ} \mathrm{C} \\
10 \mathrm{~min} \\
\text { Oil }\end{array}$ & $600^{\circ} \mathrm{C}$ & & 13,6 \\
\hline
\end{tabular}




\section{Results and Discussion}

\subsection{Ic- coercimetry}

The fig. 1 shows the dependences of the KIFM-1 coercimeter readings (Ic-coercimetry) on the absolute values of the coercive force of three groups of sample. It can be seen that the measurement of the coercive force $H_{c}$ more than (45-50) A/cm by the magnitude of the demagnetizing current is impossible for all standard sizes of samples, as noted earlier in [2$5,10]$. This limitation is explained by the fact that with an increase in the measured values $H_{c}$, the magnetic resistance of the product will increase, since an increase in the coercive force of ferromagnetics is almost always accompanied by a decrease in their magnetic permeability [20], which, in turn, under certain conditions, causes a violation of proportionality between the measured value $H_{c}$ and the demagnetizing current $I_{c}$. This conclusion is confirmed by the data in Fig. 1 . It can be seen that at comparable $\left(H_{c} \approx 80\right.$ $\mathrm{A} / \mathrm{cm}$ ) values of the coercive force, the samples N18K9M5T with a smaller cross-sectional area correspond to significantly lower values of the demagnetizing current $I_{c}$.

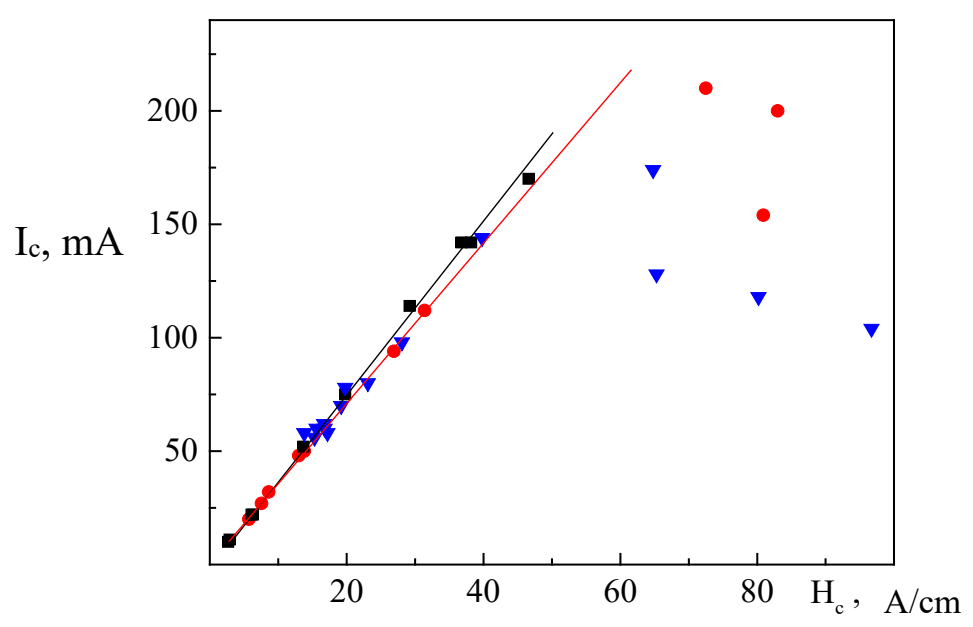

Fig. 1. Dependence of the KIFM-1 coercimeter readings on the absolute values of the coercive force of the samples of three groups: CFSS $(\square)$, RMI $(\mathbf{)}$ ) and N18K9M5T ( $)$.

Thus, Ic-coercimetry has a fundamentally limited measurement range both from below (no more than the coercive force of the magnetic circuit of the attached transducer [2-5]) and from above.

\section{$3.2 \mathrm{H}$ - coercimetry}

The fig. 2 shows the calibration dependence of the coercive force measurement in the range from 2.5 to $87 \mathrm{~A} / \mathrm{cm}$ obtained using the DIUS-1.15M, which uses a U-shaped electromagnet with a cross section of $12 \times 28 \mathrm{~mm}$ poles for magnetization. As can be seen 
from the figure, the linear dependence of the instrument readings on the value is only in the range from 2.5 to $47 \mathrm{~A} / \mathrm{cm}$. At higher values of the coercive force, the DIUS-1.15M readings have lower values. The supposed reason for this deviation may be an insufficient level of magnetization of the test area of the samples.

To check the assumption made, measurements of the coercive force were carried out on the same samples using an MMT-3 magnetic multitester with the same pole section $12 \times 28$ $\mathrm{mm}$ as for the DIUS-1.15M, but using a rotor containing a strong permanent magnet. The magnetic flux generated by such device is significantly higher than the maximum magnetic flux of the DIUS-1.15M. The fig. 3 shows the dependence of the readings of the MMT-3 magnetic multitester on the coercive force of the samples, varying in the range from 2.5 to $87 \mathrm{~A} / \mathrm{cm}$. It can be seen that in this case the linear dependence remains in the entire investigated range (correlation coefficient $\mathrm{R}=0.997$ ).

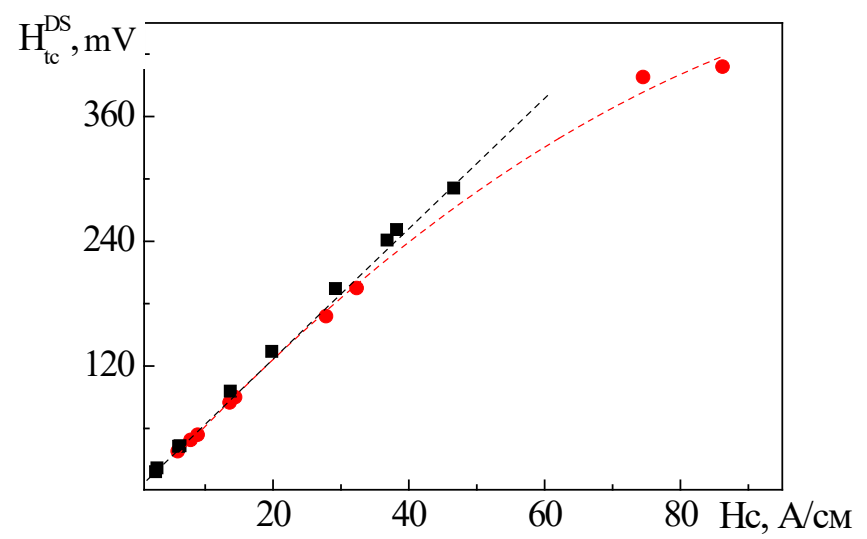

$\mathrm{A} / \mathrm{cm}$

Fig. 2. Calibration dependence of DIUS-1.15M HSS readings on absolute values of the coercive force of samples of various standard sizes: CFSS $(\square)$, RMI ( $)$.

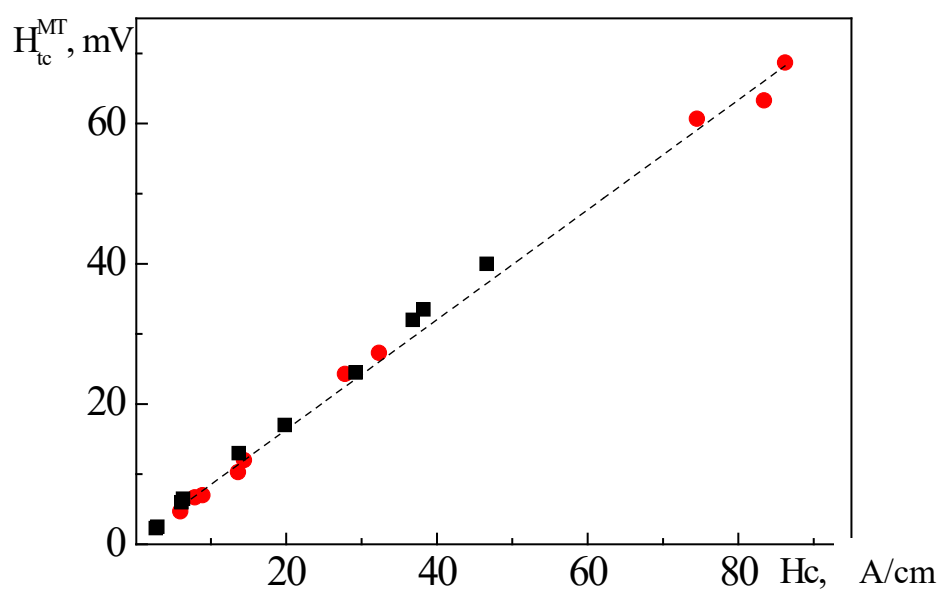

Fig. 3. Dependence of the coercimetric readings of the MMT-3 magnetic multitester on the absolute values of the coercive force of samples of various standard sizes: CFSS ( $\mathbf{\square})$, RMI (O).

Thus, when the test objects are magnetized to a state close to technical saturation, the measurement of the tangential component of the magnetic field on the surface of the object in the interpolar space (i.e., the measurement of the internal magnetic field) provides at 
least a twofold increase in the measured values in comparison with the coercimetry for the demagnetizing current.

\section{Conclusion}

It has been shown that the local measurement of the coercive force using an attached transducer with a U-shaped electromagnet in terms of the magnitude of demagnetizing current has a fundamental limitation on the measurement range. The limitation of the maximum measured value of the coercive force is due to the lower value of the magnetic resistance of the tested product. It is shown that the determination of the coercive force using a two-pole transducer is based on the magnitude of the tangential component of the magnetic field, measured near the surface of the test object in the interpolar space, i.e. by the internal field, allows you to significantly expand the measurement range. The upper measurement limit is determined only by the possibility of magnetizing the controlled object, i.e. the size and shape of the transducer and the magnetomotive force generated by it.

The research was carried out within the state assignment of Ministry of Science and Higher Education of the Russian Federation (theme "Diagnostics" No. AAAA-A18-118020690196-3, theme "Expertise" No. AAAA-A19-119062590007-2)

\section{References}

1. M.N. Miheev, Zavod. lab. 1938. № 10. C. 1155-1160.

2. M.N. Miheev, B.M. Neizvestnov, V.M. Morozova, G.V. Surin, Defektoskopiya, 2, 131-133 (1969)

3. A.V. Zagajnov, A.I. Ul'yanov, R.P. Petrov, S.G. Novikov, Defektoskopiya, 10, 60-64 (1991)

4. E.S. Gorkunov, V.A. Zaharov, Defektoskopiya, 8, 69-88 (1995).

5. 5 G.V. Bida, A.P. Nichipuruk, RJNDT, 36, 707-727 (2000)

6. G.YA. Bezlyud'ko, V.F. Muzhickij, V.B. Remezov, Defektoskopiya, 4, 43-51 (2003)

7. A.P. Nichipuruk, G.V. Bida, T. P. Tsarkova and other, RJNDT, 46, 580-586 (2010)

8. V.N. Kostin, O. N. Vasilenko, RJNDT, 48, 401-410 (2012)

9. A.E. SHubochkin, Kontrol'. Diagnostika, 8, 18-22 (2014)

10. A.P. Nichipuruk, A.N. Stashkov, V.N. Kostin i dr., V mire nerazrushayushchego kontrolya, 18, 9-13 (2015)

11. YU.L. Gobov, S.V. ZHakov, A.V. Mihajlov, Defektoskopiya, 11, 27-32 (2017)

12. V.N. Kostin, T.P. Tsarkova, E.Yu. Sazhina, RJNDT, 37, 10-19 (2001)

13. V.N. Kostin, A.A. Osincev, A.N. Stashkov and other, RJNDT, 44, 280-289 (2008)

14. V.A. Zaharov, S.M. Molin, S.V. Len'kov, Defektoskopiya, 2, 53-59 (2017)

15. YU.YA. Reutov, V.I. Pudov Defektoskopiya, 12, 40-45 (2017)

16. V.N. Kostin, O.N. Vasilenko, A.V. Byzov, RJNDT, 54, 9, 654-661 (2018)

17. YU.L. Gobov, S.V. ZHakov, A.V. Mihajlov, YU.YA. Reutov, RJNDT, 55, 935-941 (2019)

18. V.I. CHechernikov, Magnitnye izmereniya (Izd-vo MGU, M.,1969) 
19. V.I. Pudov, V.N. Kostin, A.N. Stashkov, A.A. Osincev, Ustrojstvo dlya lokal'nogo namagnichivaniya ferromagnitnyh izdelij. Patent RF na izobretenie № 2250475. Byull. № 11, 20.04.2005.

20. S.V. Vonsovskij, YA.S. SHur, Ferromagnetizm (OGIZ - Gostekhizdat, M. - L., 1948) 